Disponível em: http://periodicos.ufpb.br/ojs2/index.php/recfin

\title{
A UTILIZAÇÃO DO TWITTER NA ANÁLISE DO DISCLOSURE VOLUNTÁRIO DAS EMPRESAS BRASILEIRAS COM NÍVEIS DIFERENCIADOS DE GOVERNANÇA CORPORATIVA ${ }^{1}$
}

\author{
THE TWITTER USING IN THE ANALYSIS OF DISCLOSURE VOLUNTEER \\ OF BRAZILIAN COMPANIES WITH DIFFERENT LEVELS \\ CORPORATE GOVERNANCE
}

\author{
Sandriele Leite Mota ${ }^{2}$ \\ Mestranda em Ciências Contábeis pelo Programa de Pós-graduação em Ciências Contábeis \\ sandriele.leite@hotmail.com

\section{Suelem Katherinne de Macedo Pinto} \\ Mestranda em Ciências Contábeis pelo Programa de Pós-graduação em Ciências Contábeis \\ suelemmacedo@hotmail.com
}

\begin{abstract}
RESUMO
Objetivo: O objetivo foi analisar o nível de disclosure voluntário das companhias brasileiras de capital aberto, por meio da rede social Twitter, considerando para tanto as empresas que aderiram aos níveis diferenciados de Governança Corporativa da BM\&FBovespa.

Fundamento: Tendo em vista que as empresas que aderem aos níveis diferenciados de governança corporativa possuem maior preocupação com a transparência das informações aos agentes interessados e analisando o fato de que as redes sociais possibilitam o acesso a informação com menores custos de divulgação, tem-se como hipótese que empresas com melhores níveis de governança corporativa vão apresentar melhores níveis de disclosure voluntário nas suas contas oficiais do Twitter. Método: Desta forma, partiu-se das empresas que compõem o índice Ibovespa que possuíam contas oficiais na rede social Twitter, no período de janeiro a junho de 2016, resultando numa amostra de 64 observações. Utilizou-se o modelo logístico ordinal, cuja variável explicativa consistiu no Nível de Governança (NG) e as variáveis de controle inseridas no modelo foram tamanho (TAM) que corresponde ao logaritmo natural do ativo total, o setor (SETOR) como variável para medir a regulação e a alavancagem (ALAV).
\end{abstract}

\footnotetext{
${ }^{1}$ Artigo recebido em: 15/09/2016. Revisado por pares em: 20/10/2016. Reformulado em: 21.11.2016. Recomendado para publicação em: 21/11/2016 por Luiz Felipe de Araújo Pontes Girão (Editor Adjunto). Publicado em: 01/01/2017. Organização responsável pelo periódico: UFPB.

${ }^{2}$ Endereço: Universidade Federal da Paraíba, Campus I, CCSA, Cidade Universitária, s/n, Castelo Branco, CEP 58.059-900, João Pessoa/PB.

DOI: http://dx.doi.org/10.18405/recfin20170102
} 
Resultados: Os resultados apontaram que a partir do teste McFadden $\mathrm{R}^{2}$ (também conhecido como pseudo $\mathrm{R}^{2}$ ), verificou-se que o desempenho do modelo analisado comparativamente ao modelo reduzido (apenas com o intercepto) consistiu em 10,13\%, e apenas a variável de controle "tamanho" se comportou estatisticamente significante com o disclosure voluntário no Twitter, representando que as empresas maiores tem mais probabilidade de divulgarem informações voluntárias, comparativamente a empresas menores.

Contribuições: os achados da pesquisa, em sua maioria, divergiram do encontrado em outros trabalhos, numa análise específica das redes sociais, a partir de informações voluntárias.

Palavras-chave: Disclosure Voluntário; Governança Corporativa; Twitter.

\section{ABSTRACT}

Objective: The objective was to analyze the level of voluntary disclosure of Brazilian publicly traded companies, through the social network Twitter, considering for both companies that adhered to the differentiated levels of Corporate Governance of the BM\&FBovespa.

Background: Considering that companies that adhere to differentiated levels of corporate governance are more concerned with the transparency of information to stakeholders and analyzing the fact that social networks provide access to information with lower costs of disclosure, It is hypothesized that companies with better levels of corporate governance will present better levels of voluntary disclosure in their official Twitter accounts.

Method: Based on the companies that make up the Ibovespa index, which had official accounts on the social network Twitter, from January to June 2016, resulting in a sample of 64 observations. It was used the ordinal logistic model, whose explanatory variable was the Governance Level (NG) and the control variables included in the model were TAM, which corresponds to the natural logarithm of the total assets, the sector (SECTOR) As a variable to measure regulation and leverage (ALAV).

Results: The results of the McFadden R2 test (also known as pseudo R2) showed that the performance of the analyzed model compared to the reduced model (only with the intercept) consisted of $10.13 \%$, and only the variable Of control "size" behaved statistically significant with the voluntary disclosure on Twitter, representing that larger companies are more likely to disclose voluntary information compared to smaller companies.

Contributions: the research findings, for the most part, diverged from that found in other studies, in a specific analysis of social networks, based on voluntary information.

Keywords: Voluntary Disclosure; Corporate Governance; Twitter.

\section{INTRODUÇÃO}

Com a expansão e o fortalecimento do mercado de capitais, a transparência dos negócios praticados entre as empresas se tornou indispensável, permitindo o acesso aos diversos agentes sociais interessados. A divulgação voluntária das informações das empresas de natureza econômica, social e ambiental possibilita uma aproximação entre os usuários da informação permitindo que o mercado atribua valor a empresa (Tinoco \& Kraemer, 2004)

Na visão tradicional de Friedman (1963), apenas os shareholders representam os agentes interessados e para quem as empresas voltam seus esforços com vista à obtenção de lucros. Divergindo disso, alguns estudiosos apontaram a influência de agentes indiretos (stakeholders) na vida das empresas, sendo necessário uma divulgação abrangente para alcançar todos os entes interessados (Donaldson \& Preston, 1995).

O disclosure das informações financeiras das empresas permite à gestão divulgar a governança e o desempenho das companhias aos stakeholders (Healy \& Palepu, 2001). Os autores argumentam 
que o disclosure atua mitigando a assimetria informacional existente nas organizações decorrente do conflito de interesses tratado na Teoria da Agência (Jensen \& Meckling, 1976).

De maneira obrigatória, o disclosure pode ser realizado por meio de relatórios financeiros regulamentados, como demonstrações contábeis, relatórios de gestão, previsões de analistas, comunicados ao mercado, sites oficiais, entre outros. Todavia, o disclosure das empresas pode exceder o que é exigido por lei configurando o disclosure voluntário.

A divulgação voluntária pode trazer benefícios às empresas como redução do custo do capital próprio e do capital de terceiros, aumento da liquidez das ações e aumento do acompanhamento dos analistas (Botosan, 1997, Hail, 2003, Francis, Krurana \& Pereira, 2005, Alencar, 2007, Lima,2007, Welker, 1995, Leuz \& Verrecchia, 2000). Porém, pode acarretar custos para a preparação dessas informações, sendo necessário a avaliação dos gestores quanto aos benefícios e os custos para disclosure voluntário (Verrecchia, 2001).

A divulgação das informações pode ser feita por canais oficiais ou por meios alternativos, as redes sociais estão inseridas como canais de divulgação alternativos em que as empresas podem fazer o disclosure voluntário alicerçando com rapidez os stakeholders. Uma das redes sociais com destaque é o Twitter, este micro-blogging possui como característica o compartilhamento de mensagens curtas, de até 140 caracteres. Lançado em 2006, esta ferramenta de compartilhamento de dados gratuitos possui cerca de 320 milhões de usuários pelo mundo em 2016.

A partir de estudos preexistentes como o estudo de Gallon et al (2007) que verifica a relação existente entre o grau de evidenciação nos relatórios da administração e o nível de governança que se encontram as empresas participantes do novo mercado e dos níveis diferenciados da Bovespa; assim como o estudo de Murcia e Santos (2009) onde as empresas com melhores práticas de governança corporativa tiveram melhores níveis de disclosure voluntário; assim como o de Cormier et al (2009) que afirmam que a internet tem instigado as companhias a adaptarem suas estratégias de divulgação, pois existe mais flexibilidade do que os meios tradicionais de comunicação; como também em pesquisas que demonstram que esse tipo de divulgação é capaz de diminuir o custo de capital próprio (ke), assinalando que o ambiente informacional é um fator importante para elucidar a relação entre disclosure voluntário e o (ke) (Botosan, 1997, Cao, Myers \& Tang \& Yang, 2014) a problemática desta pesquisa fica definida na seguinte questão: as empresas com níveis diferenciados de governança corporativa possuem melhores níveis de disclosure voluntário a partir das suas contas oficiais do Twitter?

Tendo em vista que as empresas que aderem aos níveis diferenciados de governança corporativa possuem maior preocupação com a transparência das informações aos agentes interessados e analisando o fato de que as redes sociais possibilitam o acesso a informação com menores custos de divulgação, tem-se como hipótese que empresas com melhores níveis de governança corporativa vão apresentar melhores níveis de disclosure voluntário nas suas contas oficiais do Twitter.

Portanto, o objetivo deste estudo é verificar se empresas com níveis diferenciados de governança corporativa listadas na Bovespa relativamente as empresas nos níveis tradicionais, possuem melhores níveis de disclosure voluntário, através da divulgação nas suas contas oficiais do Twitter. Para alcançar o objetivo proposto utilizou-se o IDA (Índice de Disclosure Ambiental), estruturado por Bachmann et al. (2013), e o Índice de Sustentabilidade desenvolvido por Callado (2010) que visa medir o nível de disclosure voluntário mensurando questões ambientais, sociais e econômicas.

Esta pesquisa diferencia-se dos demais estudos por investigar o disclosure voluntário nas redes sociais, sendo relevante pela pouca abordagem na literatura sobre este tema, fomentando discussões sobre a importância desta ferramenta de comunicação alternativa para as empresas, em que as informações são compartilhadas aos stakeholders, em tempo real, ao redor do mundo. 


\section{REFERENCIAL TEÓRICO}

\subsection{Teoria da Divulgação}

A teoria da divulgação vem sendo estudada internacionalmente desde a década de 80 , e tem como principal objetivo explicar o fenômeno da divulgação de informações financeiras, a partir de diversas perspectivas, como por exemplo, determinar qual é o efeito da divulgação de demonstrações contábeis no preço das ações, explicar quais as razões econômicas para que determinada informação seja divulgada voluntariamente etc. (Salotti \& Yamamoto, 2005).

Diante disso, o total do Disclosure de uma empresa compreende toda informação útil e significante para tomada de decisões de seus investidores, o que permite ir além da parte que é regulada legislativamente. O Disclosure pode ser classificado tanto como compulsório como voluntário, compulsório quando remete a informações para registro das companhias abertas e demais informações exigidas pela Comissão de Valores Mobiliários; e voluntário, quando não envolve informações exigidas pela legislação, porém proporcionam ainda mais transparência para as empresas. Importante frisar que as informações divulgadas, além de quantitativas e qualitativas, podem ser positivas e negativas. Goulart (2003) traz que para se obter transparência, faz-se necessário que as empresas divulguem tanto as informações positivas, como também as negativas. Assim sendo, a transparência das informações divulgadas apresenta a oportunidade de os investidores tomarem suas decisões de acordo com julgamentos adequados diante as informações emitidas, sem qualquer viés.

Verrecchia (2001) apresenta base teórica ampla para possibilitar o desenvolvimento de pesquisas na área de Disclosure, em seu estudo apresentou três modelos importantes que abrangem a teoria da divulgação e ofereceu relações que buscam representar a divulgação e as variáveis relacionadas, são eles:

- Pesquisa sobre Divulgação baseada em Associação (association-based disclosure);

- Pesquisa sobre Divulgação baseada em Julgamento (discretionary-based disclosure);

- Pesquisa sobre Divulgação baseada em eficiência (efficiency-based disclosure).

O primeiro modelo "Association-based disclosure" analisa pesquisas com o desígnio principal de averiguar a relação entre a divulgação e as alterações dos comportamentos dos investidores, com característica basilar de avaliar os efeitos da divulgação sobre os preços dos ativos em equilíbrio e seus volumes de negócios; o segundo modelo "discretionary-based disclosure" aborda como os gestores e/ou empresas resolvem divulgar suas informações, analisando o mercado de capitais como o consumidor exclusivo das divulgações dos relatórios financeiros das empresas; e o terceiro modelo "efficiency-based disclosure" abrange quais mecanismos de divulgação são preferidos na carência de conhecimento prévio sobre a informação (ex ante).

No Brasil, as pesquisas sobre a teoria da divulgação principiaram por meados de 2005, por meio das pesquisas de Salotti (2005) e Yamamoto (2005). Salotti trouxe em seu estudo a teoria da divulgação embasada na Associação, onde analisou através de 5 hipóteses a relação entre a publicação das Demonstrações de Fluxo de Caixa e outras variáveis.

Yamamoto (2005), buscou avaliar a significância da divulgação no mercado de capitais brasileiro, procurando verificar qual a influência no nível da divulgação das informações voluntárias, da Teoria da Divulgação baseada em Associação e verificou um resultado em que demonstra que os investidores atribuem importância às informações.

Destaca-se ainda nas pesquisas realizadas no Brasil, o estudo de Callado (2010) que teve como objetivo propor e testar um modelo para mensuração da sustentabilidade empresarial concebido a partir da integração das dimensões ambiental, social e econômica, e também a pesquisa de Bachmann et al. (2013) que teve como objetivo elencar atributos ambientais, conforme o grau de importância de disclosure, para composição de um indicador genuinamente brasileiro que avalie qualidade de evidenciação de informações ambientais. Ambos estudos trouxeram embasamento para utilização da variável dependente utilizada para esta pesquisa, denominada Índice de Disclosure Voluntário (IDV), 
que é uma adaptação dos índices IDA (Índice de Disclosure Ambiental) estruturado por Bachmann $e t$ al. (2013), validado por Altoé, Panhoca e Espejo (2015), e o Índice de Sustentabilidade desenvolvido por Callado (2010) posteriormente estudado por Feil e Naime (2015).

Verrecchia (2001) constatou uma relação positiva entre as divulgações voluntárias e as receitas das empresas e pôde concluir que se não existem custos de divulgação, a empresa recebe incentivo para divulgar toda informação sem custo. Porém, a medida que os custos de divulgação aumentam, as empresas são desestimuladas a divulgar mais informações voluntariamente, concluindo que, o benefício da divulgação deve ser superior ao custo, para que a empresa se sinta compelida à divulgação voluntária (Sousa, 2013).

A obrigatoriedade da transparência e divulgação das informações contábeis é prevista na Lei nº 6.404/76 alterada pela Lei $\mathrm{n}^{\mathrm{o}}$ 11.638/08, que aborda os relatórios financeiros das sociedades anônimas. Através da legislação, é obrigatório que as empresas disponibilizem as suas informações através das demonstrações contábeis. E através destas, deve-se obter clareza sobre as informações patrimonial das empresas, assim como as mudanças ocorridas durante o exercício. A divulgação obrigatória possui função de oferecer credibilidade a divulgação voluntária, ou seja, tem papel secundário, a qual é vista como uma fonte primária da informação que possibilita a verificação da veracidade da divulgação voluntária (Yamamoto \& Salotti, 2006).

Verrecchia (2001) afirma ainda que uma questão primordial e que merece atenção da literatura contábil, seja teoria normativa ou positivista, é a relação entre publicidade e informação de redução da assimetria. Pois, essa relação liga divulgação a eficiência e, assim sendo, fornece uma justificativa econômica para utilidade dos relatórios financeiros.

\subsubsection{Disclosure Voluntário}

O fundamental desígnio da Teoria da Divulgação é elucidar o fato da divulgação das informações financeiras das empresas. Verrecchia (2001), pondera que não há uma teoria da divulgação abrangente ou unificada, já que conforme ele não há nenhum paradigma central, nem uma única noção convincente que dá origem a todas as pesquisas subsequentes. Posicionamento esse contraposto por Dye (2001), que avalia ser essa teoria, um caso especial da teoria dos jogos, com a premissa central de que a entidade irá divulgar informações favoráveis, ao mesmo tempo em que não divulgará informações desfavoráveis.

O presente estudo, em razão de seu objetivo, embasa-se na Divulgação baseada em Julgamento conhecida como Teoria do Disclosure Voluntário. Como já abordado acima a premissa central dessa teoria, segundo Verrecchia (2001), é de que disclosure é um evento endógeno, sendo que os gestores e/ou empresas possuem incentivos econômicos para divulgar, ou não, informações de maneira voluntária, uma vez que os usuários externos das demonstrações contábeis são os consumidores dessas informações.

Lima et al. (2007) traz que o disclosure pode ser tanto obrigatório; contemplando diversas obrigações regulamentadas expedidas por órgãos oficiais e governo, como voluntário envolvendo informações discricionárias de natureza qualitativa e quantitativa em relatórios elaborados para tais fins, visando aumentar a transparência e reduzir a assimetria informacional. Goulart (2003) define transparência quando a empresa divulga tanto informações positivas como também as negativas, pois agindo assim contribui para informar com fidedignidade a real situação das empresas.

Sousa (2013) argumenta que a transparência proveniente da iniciativa de divulgação voluntária tende a contribuir de forma positiva e favorecer os aspectos inerentes à atividade empresarial. Além de que, divulgar de forma voluntária informações que não são obrigatórias pela legislação traz uma forma de diferenciação aos interessados, trazendo de certo mais credibilidade e visibilidade para as empresas que concretizam essa ação. 


\subsubsection{Estudos vinculados à Divulgação Alternativa}

Apesar de ser um tema ainda pouco estudado na literatura há alguns trabalhos que abordam a divulgação alternativa e originam resultados importantes para a temática. Alguns autores relacionaram outros temas como a assimetria de informação e também a precificação das ações com a utilização de redes sociais.

O trabalho realizado por Hu et al. (2011) teve como escopo averiguar o impacto positivo originado por blogs na avaliação de ações, assim como analisar esses impactos no mercado de capitais. Já Drake et al. (2012) desdobraram-se para analisar fatores que oferecem impacto na busca dos investidores por informações relacionadas aos resultados das companhias, como a utilização do site de buscas Google como meio de acesso para essas informações. O resultado observou um aumento de busca no site cerca de duas semanas antes da divulgação, mantendo-se elevada por um certo período após o anúncio dos resultados divulgados pelas companhias.

Quanto ao estudo realizado por Blankespoor et al. (2014), foi utilizado a ferramenta twitter para analisar se as companhias conseguem utilizar essas tecnologias para diminuir a assimetria informacional, não há conclusão que a rede social impacte na visibilidade da companhia, porém há um consenso de que uso dessa ferramenta pode subsidiar na mitigação de assimetria informacional para empresas que não são tão visíveis.

No Brasil, alguns estudos já abordam a temática. Arruda et al. (2015) tiveram como desígnio analisar o modo pelo qual as redes sociais (Facebook, Twitter e Youtube) afetam o nível de assimetria informacional e a precificação das ações das companhias abertas, tanto brasileiras como estadunidenses. Os autores verificaram que as redes sociais podem afetar o nível de assimetria informacional nesses mercados, mas apenas o Facebook "não oficial" afeta a precificação das ações nas empresas do mercado brasileiro, entretanto na análise de sensibilidade realizada verificou-se que os grupos dos que usam ou não o Facebook não apresenta retornos médios diferentes, trazendo assim que os investidores não devem utilizar essa informação para traçar estratégias que gerem melhores retornos.

Um outro estudo brasileiro de Arruda et al. (2015) teve como objetivo observar se a utilização das redes sociais (Wikipédia, YouTube e Facebook) reduz a assimetria de informação existente entre as empresas e os investidores. Os resultados apontaram que a utilização das redes sociais não tem forte influência nos erros de previsão dos analistas (proxy utilizada para a assimetria informacional).

\subsection{Governança Corporativa}

Conforme as diretrizes de Governança Corporativa divulgadas pela BM\&FBovespa, a premissa fundamental é que se obtenha melhoria da qualidade das informações usualmente prestadas pelas companhias abertas, assim como ampliação dos direitos dos acionistas que reduzirão o risco do negócio, já que amortizam dúvidas diante o investimento. E essa premissa, gera como consequências um rol de fatores que trarão mais visibilidade e benefícios para as companhias, como melhoria na precificação das ações, que pode provocar novas aberturas de capital e também novas emissões, e em especial, através dessa premissa pode-se elevar a disposição de investidores de contrair novas ações.

Com o intuito de ambientar o mercado de negociações, estimulando investidores a adquirir ações e valorizando as empresas foram desenvolvidos segmentos especiais de Governança Corporativa, são eles: Nível 1, Nível 2 e Novo Mercado. Segundo Besarria et.al (2015) a maior parte dos compromissos que as empresas do Nível 1 assumem perante os investidores se refere ao fornecimento de informações que auxiliam na avaliação sobre o valor da empresa, já a diferença de Novo Mercado e o Nível 2 se refere à emissão de ações preferenciais. Enquanto as empresas do Novo Mercado somente possuem ações ordinárias, as empresas do Nível 2 têm ações preferenciais. 
Sabendo da natureza e do objetivo dos segmentos especiais de Governança Corporativa, intuito de melhoria da qualidade de informações e transparência das mesmas, o estudo vincula a ferramenta de comunicação Twitter - um meio que possibilita o uso do Disclosure Voluntário - com a Governança Corporativa, que é um instrumento que, possivelmente, contribui para esse acontecimento.

\subsection{Redes Sociais: Twitter}

A sociedade civil contemporânea submersa numa atmosfera cada vez mais tecnológica, acessível, prática e ligada via internet tende cada dia mais a constituir-se diante dos meios sociais, como as distintas redes sociais virtuais que já existem.

As redes sociais virtuais podem contribuir para diminuir a assimetria informacional entre os diversos interessados nas atividades da firma. Para as empresas, as redes possibilitam também a redução do custo de publicações de marketing de vendas, assim como reduzir o custo de disponibilizar conhecimento suficiente sobre suas transações, valor de suas cotações, reconhecimento de clientes, entre outros, praticamente sem grandes gastos financeiros (Arruda et al., 2015).

Nas últimas décadas, as redes sociais têm amadurecido, consideravelmente, com a imersão de milhões de seguidores e com a quantidade de dados emitidos em suas redes através de seus usuários, tornando-se uma fonte de buscas e acesso rápido, assim como uma ferramenta atrativa para investidores que através destas redes podem captar informações que diminuam a assimetria informacional. Em conjunto, traz também impactos na forma de conduzir a comunicação, afetando a divulgação, sejam elas obrigatórias ou voluntárias, das informações contábeis das empresas.

Dentro das importâncias que as redes sociais impactam, Junqueira (2008) traz o debate de como as redes sociais podem ser constituídas como ação estratégica e para o empreendedorismo social. Acrescenta-se que, além das ações estratégicas que as redes sociais podem trazer, são consideradas como meios que podem afetar e diminuir a assimetria de informações para investidores com a sua utilização (Arruda, Girão \& Lucena, 2015), impactando no mercado financeiro e sendo meio facilitador para o uso e divulgação.

Mendes-da-Silva et al. (2014) apresenta uma análise entre a existência de associações entre o disclosure voluntário via website corporativo e o custo de capital ex ante de empresas listadas na BM\&FBovespa, concluindo que tais métricas não estão associadas a nenhuma proxy de custo de capital analisada no trabalho. Assim sendo, diante das da forma de evidenciação das informações das empresas, o presente trabalho propõe-se a estudar uma rede social específica, o micro-blogging Twitter e a analisar o Disclosure voluntário através do mesmo com as empresas que possuem níveis diferenciados de governança corporativa.

\section{METODOLOGIA}

\subsection{Caracterização da Amostra}

A pesquisa caracteriza-se como descritiva, adotando-se para atender ao objetivo proposto, abordagem quantitativa, com procedimentos documentais, utilizando-se de dados secundários provenientes do disclosure voluntário das empresas. Para tanto, foram investigadas as empresas brasileiras de capital aberto que compõem o Índice Bovespa - Ibovespa.

A seleção da amostra foi feita a partir do filtro padrão do Economatica ${ }^{\circledR}$, mostrando apenas uma classe de ações por empresas: aquela com maior volume no último mês. O período de coleta de dados correspondeu aos meses de janeiro a junho de 2016, buscando obter resultados mais recentes, diretamente na conta oficial do Twitter de cada empresa. Foram eliminadas da amostra as empresas financeiras e as empresas que não tinham conta oficial no micro-blogging Twitter, resultando em 64 empresas. 
Para efetuar as devidas análises, a amostra foi segregada em dois grupos: a) empresas que aderiram as boas práticas de governança corporativa da BM\&FBovespa N1, N2 e Novo Mercado e b) empresas que não aderiram as boas práticas de governança corporativa da BM\&FBovespa N1, N2 e Novo Mercado. A amostra para análise ficou composta conforme detalhamento da Tabela 1. Este agrupamento ocorreu baseando-se em estudos anteriores que verificaram uma relação positiva entre níveis de disclosure e os segmentos de governança corporativa listados na BM\&FBovespa (Lanzana, 2004, Gallon, Beuren \& Hein, 2007).

Tabela 1: Composição da amostra

\begin{tabular}{c|c|c}
\hline $\begin{array}{l}\text { Empresas com níveis diferenciados de } \\
\text { governança corporativa }\end{array}$ & $\begin{array}{l}\text { Empresas com governança corporativa } \\
\text { tradicional }\end{array}$ & Total \\
\hline 56 & 8 & 64 \\
\hline
\end{tabular}

Fonte: elaboração dos autores

\subsection{Coleta dos Dados}

Os dados foram coletados e catalogados utilizando-se a adaptação de dois índices já descritos na literatura pertinente, o IDA (Índice de Disclosure Ambiental) estruturado por Bachmann et al. (2013) e o Índice de Sustentabilidade desenvolvido por Callado (2010) que visa medir o nível de disclosure voluntário mensurando questões ambientais, sociais e econômicas.

Para a contagem do disclosure voluntário, foi utilizada a análise das postagens do Twitter, na página oficial de cada empresa. De acordo com os itens propostos na tabela 2, foi a atribuída pontuação entre 0 e 1, para as empresas que divulgam e não divulgam informações pelas contas oficiais do Twitter, respectivamente. Após a contagem da pontuação obtida em cada item, dividiu-se pelo total de itens que estavam contidos no check-list (total de 33 itens). 
Tabela 2 - Disclosure voluntário das empresas na conta oficial do Twitter.

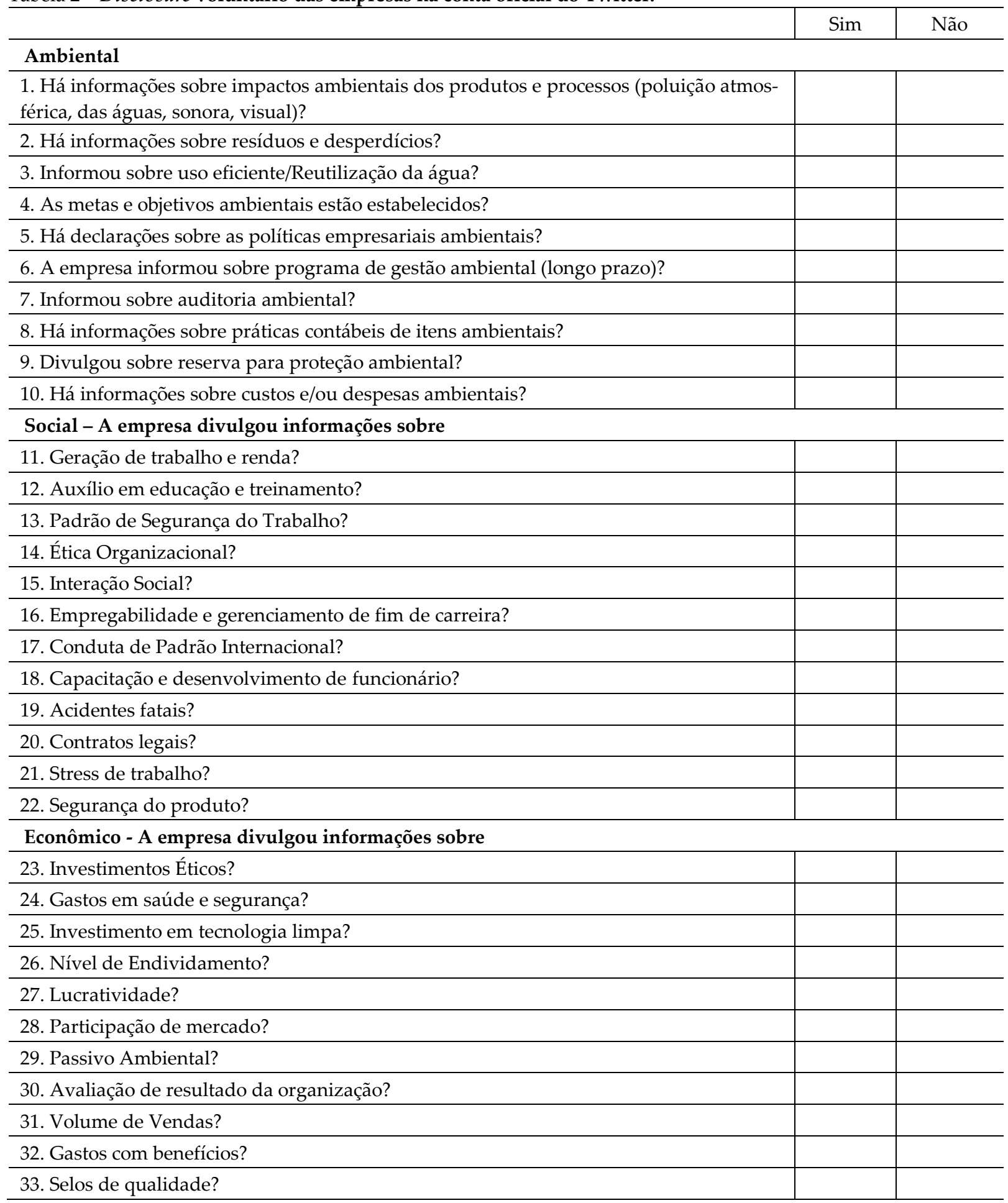

Fonte: Adaptado de Callado (2010) e Bachmann et al. (2013) 


\subsection{Caracterização da variável dependente e variáveis independentes}

A variável dependente utilizada para esta pesquisa foi o Índice de Disclosure Voluntário (IDV), uma adaptação dos índices IDA (Índice de Disclosure Ambiental) estruturado por Bachmann et al. (2013), validado por Altoé, Panhoca e Espejo (2015) e o Índice de Sustentabilidade desenvolvido por Callado (2010) posteriormente estudado por Feil e Naime (2015). O IDV se propõe capturar o nível de evidenciação ambiental, econômico e social analisando o nível de transparência das informações empresariais através da rede social Twitter. As variáveis independentes utilizadas no modelo são demonstradas no Quadro 1.

Quadro 1 - Resumo das variáveis independentes utilizadas para explicar o IDV

\begin{tabular}{|c|c|c|c|c|}
\hline Tipo & $\begin{array}{c}\text { Variáveis Indepen- } \\
\text { dentes }\end{array}$ & Mensuração & Sinal Esperado & Sustentação Teórica \\
\hline 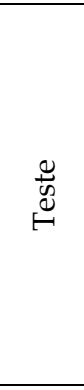 & $\begin{array}{ll}\text { Nível de Gover- } \\
\text { nança } & \text { Corporativa } \\
(\mathrm{NG}) & \end{array}$ & $\begin{array}{l}\text { Números naturais de } 1 \text { a } 4 \text {, represen- } \\
\text { tando o segmento de governança } \\
\text { corporativa ao qual as empresas per- } \\
\text { tencem: } 1 \text { para mercado tradicional } \\
\text { de governança corporativa e } 2,3 \text { e } 4 \\
\text { para os níveis diferenciados de go- } \\
\text { vernança corporativa da BM\&FBo- } \\
\text { vespa N1, N2 e Novo Mercado, res- } \\
\text { pectivamente. }\end{array}$ & $(+)$ & $\begin{array}{l}\text { Murcia \& Santos } \\
(2009)\end{array}$ \\
\hline \multirow{3}{*}{$\begin{array}{l}\frac{0}{0} \\
\stackrel{7}{0} \\
0 \\
0\end{array}$} & Tamanho (TAM) & Ln do Ativo Total & $(+)$ & $\begin{array}{l}\text { Nakayama \& Salotti } \\
(2014)\end{array}$ \\
\hline & $\begin{array}{l}\text { Alavancagem } \\
(\mathrm{ALAV})\end{array}$ & $\begin{array}{l}\text { Passivo Exigível/ Patrimônio Lí- } \\
\text { quido }\end{array}$ & $(+)$ & $\begin{array}{l}\text { Ribeiro, Bellen \& Car- } \\
\text { valho (2011), Moraes, } \\
\text { Gonçalves \& Niyama } \\
(2015)\end{array}$ \\
\hline & Setor (SET) & $\begin{array}{l}\text { Binária - sendo } 1 \text { para as empresas } \\
\text { do setor elétrico (empresas regula- } \\
\text { das) e zero para as empresas dos de- } \\
\text { mais setores }\end{array}$ & Indeterminado & $\begin{array}{l}\text { Murcia \& Santos } \\
(2009)\end{array}$ \\
\hline
\end{tabular}

Fonte: elaboração dos autores

\subsection{Modelo Estatístico e Técnica de Análise dos Dados}

O modelo utilizado para alcançar o objetivo desta pesquisa e testar a associação entre o nível de disclosure voluntário e a governança corporativa, é assim descrito:

$$
\mathrm{ND}_{\mathrm{i}}=\beta_{1}+\beta_{2} \mathrm{NG}_{\mathrm{i}}+\beta_{3} \mathrm{TAM} \mathrm{M}_{\mathrm{i}}+\beta_{4} \mathrm{ALAV}_{\mathrm{i}}+\beta_{5} \mathrm{SET}_{\mathrm{i}}+\varepsilon_{\mathrm{i}}
$$

NDi é o nível de disclosure voluntário;

NGirepresenta o tipo de governança corporativa ao qual as empresas fazem parte;

$\mathrm{TAM}_{\mathrm{i}}=$ tamanho da empresa;

$A L A V_{i}=$ alavancagem da empresa;

$\mathrm{SET}_{\mathrm{i}}=$ setor da empresa;

$\varepsilon_{i}=$ termo de erro referente a empresa, tendo por premissa distribuição normal com média zero e variância constante e finita.

$\beta=$ coeficientes das variáveis explanatórias.

A partir das variáveis explicativas apresentadas anteriormente, a técnica estatística utilizada se refere ao logit ordenado que é empregado em situações em que a variável dependente tem caráter de mensuração qualitativa e ordinal, cuja intenção é de captar a intensidade e significância do impacto de uma série de variáveis explicativas (independentes) sobre uma variável dependente. 
Nesse caso, a variável dependente utilizada se refere ao disclosure voluntário, que para operacionalização foram estabelecidas, neste estudo, quatro categorias para a variável dependente. Portanto, os índices de disclosure voluntário no Twitter foram divididos em quartis para definir o grau de nível de disclosure, sendo: Grau 1 (de 0 até o $1^{\circ}$ quartil) - Ruim; Grau 2 (acima do $1^{\circ}$ quartil até o $2^{\circ}$ quartil) - Regular; Grau 3 (acima do $2^{\circ}$ quartil até o $3^{\circ}$ quartil) - Bom; e Grau 4 (acima do $3^{\circ}$ quartil) - Ótimo.

Desse modo, pretendeu-se investigar o efeito da variável explicativa governança corporativa elencada na pesquisa tendo seus efeitos controlados pelas características apontadas na literatura como tamanho, alavancagem e regulação (NAKAYAMA; SALOTTI, 2014; RIBEIRO; BELLEN; CARVALHO, 2011; MORAES; GONÇALVES; NIYAMA, 2015; MURCIA; SANTOS, 2009) sobre a probabilidade de ocorrência do evento de interesse, que, no caso, refere-se à classificação da divulgação das empresas no Twitter em diferentes níveis de divulgação de informações voluntárias (Ruim, Regular, Bom e Ótimo).

\section{ANÁLISE DOS RESULTADOS}

\section{1 Análise Agregada}

As empresas foram agrupadas em 4 partes, pelos quartis, para operacionalizar a Análise de Correspondência - ANACOR. A tabela 3 apresenta a separação segundo esse critério, onde as empresas receberam notas entre 1 e 4 . Os dados foram divididos em quartis para definir o grau de nível de disclosure, sendo: Grau 1 - Ruim, Grau 2 - Regular, Grau 3 - Bom, Grau 4 - Ótimo. Esta tabela apresenta ainda a separação por quatis dos níveis de governança corporativa das empresas que compõem a amostra, onde foram agrupadas: Grau 1 - para empresas que possuem governança tradicional, Grau 2 - para empresas do nível 1 (N1) de governança corporativa, Grau 3 - para empresas do nível 2 (N2) de governança corporativa e Grau 4 - para empresas do novo mercado (NM). A existência da classificação da governança corporativa em diferentes níveis pressupõe uma escala ascendente do nível tradicional até o novo mercado.

Tabela 3 - Pencentis dos Níveis de Disclosure

\begin{tabular}{ccc}
\hline Percentis & IDV & Governança Corporativa \\
\hline 5 & 1 & 1 \\
10 & 1 & 1 \\
25 & 1 & 1 \\
50 & 1 & 2 \\
75 & 2 & 4 \\
90 & 3 & 4 \\
95 & 4 & 4 \\
99 & 4 & 4 \\
\hline
\end{tabular}

Fonte: elaboração dos autores

Analisando a contingência da variação do Nível de Disclosure em relação a Governança Corporativa, têm-se os números apresentados na tabela 4. O teste do Qui-Quadrado não foi significativo já que o $p$-value foi 0,266 .

Tabela 4 - Tabela de contingência: Nível de disclosure com governança corporativa

\begin{tabular}{cccccc}
\hline \multicolumn{5}{c}{ Governança Corporativa } \\
\hline Nível de Disclosure & Tradicional & N1 & N2 & NM & Total \\
Ruim & 4 & 3 & 4 & 27 & 38 \\
Regular & 2 & 3 & 0 & 9 & 14 \\
Bom & 1 & 3 & 0 & 2 & 6 \\
Ótimo & 1 & 2 & 0 & 3 & 6 \\
Total & 8 & 11 & 4 & 41 & 64 \\
\hline
\end{tabular}

Fonte: elaboração dos autores 
Nessa relação pode-se inferir que há um disclosure "Ótimo", "Regular" e "Ruim" no Novo Mercado e um disclosure "Bom" no N1 para confirmar a análise de correspondência (ANACOR), os dados serão analisados através de modelo de regressão múltipla.

Com intuito de destacar relevantes observações do estudo, inicialmente realizou-se uma análise descritiva dos dados estudados. De acordo com a tabela 5 abaixo, a variável dependente, disclosure voluntário, apresentou média igual a 1,68 com o desvio padrão de 0,99 e mediana de valor 1 . Tendo como limite mínimo e máximo, respectivamente, 0 e 4, a mediana demonstra que o índice corresponde a aproximadamente ao seu valor mínimo. A variável independente, governança corporativa, apresentou média correspondente a 3,21 com o desvio padrão de 1,13 e mediana de valor 4, e apresenta limite mínimo e máximo de 1 e 4 , respectivamente, o que traz que essa variável está bem mais próxima de seu valor máximo, ou seja, a maioria das empresas analisadas estão enquadradas nos níveis diferenciados de governança corporativa.

Tabela 5: Análise Descritiva dos dados

\begin{tabular}{cccccc}
\hline Variável & Média & Desvio Padrão & Mediana & Mínimo & Máximo \\
\hline $\mathrm{ND}_{\mathrm{i}}$ & 1.6875 & 0.9900297 & 1 & 0 & 4 \\
$\mathrm{NGi}$ & 3.21875 & 1.133456 & 4 & 1 & 4 \\
$\mathrm{TAM}_{\mathrm{i}}$ & 6.856562 & 0.7471793 & 6,83 & 4,46 & 8,93 \\
$\mathrm{ALAV}_{\mathrm{i}}$ & 114.7231 & 235.0346 & 67,63 & -220.27 & 1656.19 \\
$\mathrm{SET}_{\mathrm{i}}$ & 0.125 & 0.3333333 & 0 & 0 & 1 \\
\hline
\end{tabular}

Nota: amostra composta por 64 observações, no período de janeiro a junho de 2016.

Legenda: - NG: nível de governança corporativa - TAM: logaritmo natural do ativo total - ALAV: alavancagem medida pelo passivo total dividido pelo patrimônio líquido.

Fonte: Resultados da pesquisa

Ao analisar as variáveis de controle, pode-se perceber que a variável TAM possui uma média de 6,85 com desvio padrão de 0,74 e mediana de 6,83. Logo, pode-se concluir que as empresas em análise possuem tamanho muito similar, já que sua mediana quase se iguala com sua média. Quando a variável analisada é a $S E T$, nota-se que a maioria das empresas não são do Setor de Energia Elétrica, já que a média desta variável corresponde a 0.125 , seu desvio padrão é de 0.33 e sua mediana tem valor 0 , o que significa que seu índice está bem mais próximo do seu valor mínimo.

Quando se observa a variável $E N D$, constata-se que de acordo com sua média, esta variável está bem mais próxima de seu limite mínimo, o que se pode concluir que as empresas da amostra não possuem índice de endividamento tão alto.

\subsection{Logit Ordenado}

Conforme já mencionado, para a operacionalização do modelo logit ordenado, os índices de disclosure voluntário das empresas brasileiras no Twitter foram divididos em quartis para definir o grau de nível de disclosure. Desse modo, os entes públicos receberam notas de 1 a 4 , de acordo com o intervalo de dados divididos pelos quartis, sendo: Grau 1 (de 0 até o $1^{\circ}$ quartil) - Ruim; Grau 2 (acima do $1^{\circ}$ quartil até o $2^{\circ}$ quartil) - Regular; Grau 3 (acima do $2^{\circ}$ quartil até o $3^{\circ}$ quartil) - Bom; e Grau 4 (acima do $3^{\circ}$ quartil) - Ótimo. Os resultados obtidos da regressão não linear utilizando a variável ND como dependente, são apresentados na Tabela 6 . 
Tabela 6: Resultados da estimação do modelo logit ordenado.

\begin{tabular}{ccccc}
\hline $\mathrm{ND}$ & Coeficiente & Desvio Padrão & $\mathrm{z}$ & $\mathrm{P}>\mathrm{z}$ \\
\hline $\mathrm{NG} i$ & -0.3006525 & 0.2363067 & -1.27 & 0.203 \\
$\mathrm{TAM}_{\mathrm{i}}$ & 1.110118 & 0.384527 & 2.89 & 0.004 \\
$\mathrm{ALAV}_{\mathrm{i}}$ & -0.0003421 & 0.0013204 & -0.26 & 0.796 \\
$\mathrm{SET}_{\mathrm{i}}$ & -0.9343309 & 0.7656907 & -1.22 & 0.222 \\
\hline
\end{tabular}

PseudoR ${ }^{2}$

$10.13 \%$

Log Verossimilhança

$-62.45$

Qui-quadrado

14.08

Qui-quadrado (valor-p)

0.007

Observações

64

Notas: Esta tabela apresenta os resultados das estimações do modelo não linear apresentado na seção 4 por meio dos estimadores logit. Amostra composta por 64 observações, no período de janeiro a junho de 2016. Legenda: NG: nível de governança corporativa - TAM: logaritmo natural do ativo total - ALAV: alavancagem medida pelo passivo total dividido pelo patrimônio líquido.

Fonte: Resultados da pesquisa

Na regressão linear, os valores de $\mathrm{R}^{2}$ relacionam a proporção da variação da variável dependente explicada pelas variáveis independentes. Para os modelos cujo método de estimação é o da máxima verossimilhança, tal como é o caso do modelo logit ordenado, utilizam-se estatísticas alternativas conhecidas como pseudo- $\mathrm{R}^{2}$ para avaliar o ajuste do modelo. Logo, a partir do teste McFadden $\mathrm{R}^{2}$ (também conhecido como pseudo $\mathrm{R}^{2}$ ), verificou-se que o desempenho do modelo analisado comparativamente ao modelo reduzido (apenas com o intercepto) consistiu em 10,13\%.

Analisando-se os sinais dos coeficientes das variáveis estatisticamente significativas (valor-p $<\alpha$ ), observa-se que apenas a variável de controle "tamanho" se comportou estatisticamente significante com o disclosure voluntário no Twitter, representando que a empresas maiores tem mais probabilidade de divulgarem informações voluntárias, comparativamente a empresas menores. Estes resultados vão de acordo com o estudo de Nakayama e Salotti (2014).

As demais variáveis - governança corporativa, alavancagem e regulação - não apresentaram significância estatística ao nível de 5\%, contrapondo-se aos achados de Moraes, Gonçalves e Niyama (2015) e Murcia e Santos (2009).

De maneira resumida, os achados da pesquisa divergiram do encontrado em outros trabalhos, numa análise específica das redes sociais, a partir de informações voluntárias. Assim, não foi encontrada relação significante entre a governança corporativa e o disclosure voluntário, principal objeto de investigação desta pesquisa.

\section{CONSIDERAÇÕES FINAIS}

Esta pesquisa teve como objetivo verificar se empresas com níveis diferenciados de governança corporativa listadas na BM\&FBovespa relativamente a empresas de governança tradicional, possuíam melhores níveis de disclosure voluntário, através da divulgação de informações econômicas, sociais e ambientais nas suas contas oficiais do Twitter, no período de janeiro a junho de 2016. Quanto ao método utilizado, após a análise da correlação entre as variáveis disclosure voluntário e governança corporativa, optou-se pelo modelo logístico ordinal.

Os resultados apontaram para uma falta de significância estatística na relação entre o disclosure voluntário no Twitter e a governança corporativa, podendo significar que as informações que são divulgadas voluntariamente não são influenciadas pelo tipo de governança corporativa ao qual 
façam parte. As variáveis inseridas para controlar o efeito do tamanho da empresa, grau de alavancagem e regulação apresentaram comportamentos diferentes entre si, onde apenas a variável tamanho apresentou significância estatística.

A partir dos resultados encontrados, é possível deduzir que a rede social Twitter é utilizada pelas empresas com finalidades diversas, que não a divulgação de informações ambientais, sociais ou econômicas. Desta maneira, a pesquisa conduz a suposição que a utilização desta rede social tem por fim objetivos publicitários, relativamente aos produtos e serviços ofertados pelas empresas.

Uma limitação da pesquisa consiste na expansão dos dados, já que estes foram coletados manualmente, nas redes sociais das empresas. Desta forma, a utilização de ferramentas computacionais para viabilizar a pesquisa, beneficiaria o desenvolvimento desta importante fase da investigação.

A respeito das contribuições, o presente trabalho agrega valor à literatura existente, como mais uma fonte de pesquisas sobre o tema disclosure voluntário nas redes sociais, no sentido em que divergindo de estudos anteriores, variáveis como governança corporativa, alavancagem e setores regulados, não afetam o nível de disclosure voluntário, quando na rede social Twitter.

Conclui-se então que esta ferramenta de divulgação, quanto a investigação da sua utilidade, é uma fonte fértil de pesquisas, considerando o seu papel na sociedade contemporânea. Algumas sugestões para trabalhos futuros envolvem a análise de outras redes sociais como Wikipédia, Facebook, Youtube, no sentido de investigar o disclosure voluntário e governança corporativa, através do uso de métodos econométricos distintos para avaliar as variáveis de interesse.

\section{REFERÊNCIAS}

Alencar, R. C.; Lopes, A. B. (2005). Custo de capital próprio e nível de disclosure nas empresas brasileiras. In: Congresso USP de Controladoria e Contabilidade, 5., São Paulo-SP. Anais...

Alencar, R. (2007). Nível de disclosure e custo de capital próprio no mercado brasileiro. Tese (Doutorado em Controladoria e Contabilidade) - Faculdade de Economia, Administração e Contabilidade, Universidade de São Paulo, São Paulo.

Altoé, S. M. L.; Panhoca, L. Espejo, M. M. S. B. (2015). Índice de Disclosure Ambiental (IDA): Análise da Aplicação de Indicador Desenvolvido a partir da Ótica de Especialistas no Brasil. XV Congresso USP de Contabilidade e Controladoria. São Paulo, 29-31 jul.

Arruda, M. P; Girão, L. F. A; Lucena, W. G. L. (2015). Assimetria Informacional e o Preço das Ações: Análise da Utilização das Redes Sociais nos Mercados de Capitais Brasileiro e Norte-americano. Revista Contabilidade \& Finanças, v.26, n.69.

Arruda, M. P; Sousa, R. A. M; Girão, L. F. A. P; Paulo, E. (2015). Divulgação de Informações por meio da Internet: Serão as redes sociais capazes de reduzir a assimetria informacional entre empresas e investidores? Revista Evidenciação Contábil \& Finanças, v. 3, n.2, p.27-41, maio/ago.

Bachmann, R. K., Carneiro, L. M., \& Espejo, M. M. dos S. B. (2013). Evidenciação de informações ambientais: proposta de um indicador a partir da percepção de especialistas. Revista de Contabilidade e Organizações, 7(17), 36-47.

Besarria, C. N. et. al. (2015). A qualidade das informações prestadas pelas empresas reduz os riscos de investimento? Uma análise empírica para os diferentes níveis de governança corporativa das empresas brasileiras. Race, Joaçaba, v.14, n.1, p. 11-38, jan/abr. 
Blankespoor, E.; Miller, G. S.; \& White, H. D. (2014). The Role of Dissemination in Market Liquidity: Evidence from Firms' Use ofTwitter. The Accounting Review, 89(1), 79-112.

Botosan, C. Disclosure level and cost of equity capital. (1997). The Accounting Review, v. 72, p. 323349.

Callado, A.L.C. (2010). Modelo de mensuração de sustentabilidade empresarial: Uma aplicação em vinícolas localizadas na serra gaúcha. Tese (Doutorado em Agronegócios) - Programa de Pós-Graduação em Agronegócios. Universidade Federal do Rio Grande do Sul, Porto Alegre.

Cao, Y; Myers, L. A.; Tsang, A.; \& Yang, Y. G. (2014). Management Forecasts and the Cost of Equity Capital: International Evidence. Asian Finance Association (AsianFa) 2014 Conference Paper, nov.

Cormier, D.; Aerts, W.; Ledoux, M. J. \& Magnan, M. Attributes of Social and Human Capital Disclosure and Information Asymmetry between Managers and Investors. (2009). Canadian Journal of Administrative Sciences, 26 (1), 71-88.

Donaldson, T. Preston, L. E. The Stakeholder Theory of the Corporation: Concepts, Evidence, and Implications. (1995). The Academy of Management Review. v. 20, n. 1, p. 65-91.

Drake, M. S.; Roulstone, D. T.; \& Thornock, J. R. (2012). Investor Information Demand: Evidence from Google Searches Around Earnings Announcements. Journal of Accounting Research, 50(4), 1001-1040.

Feil, A.A.; Naime, R H. (2015) Mensuração da sustentabilidade das corporações com selo ISE da BM\&FBovespa via modelo GSE. Revista Ambiente Contábil. v. 7, n. 1, p. 254 - 272.

Francis, J.; Khurana, I.; Pereira, Raynolde. (2005). Disclosure incentives and effects on cost of capital around the world. The Accounting Review, v. 80, p. 1125-1162.

Friedman, M. (1993). Capitalism and Freedom. University of Chicago Press.

Gallon, A. V.; Beuren, I. M.; Hein, N. (2007). Análise da relação entre evidenciação nos relatórios da administração e o nível de governança das empresas na Bovespa. Revista de Informação Contábil - RIC, v. 1, n. 2, p. 18-41, out./dez.

Goulart, A. M. C. (2003). Evidenciação Contábil do Risco de Mercado por Instituições Financeiras no Brasil. São Paulo. Dissertação (Mestrado em Ciências Contábeis) - Programa de Pós-Graduação em Ciências Contábeis, Departamento de Contabilidade e Atuária da Faculdade de Economia, Administração e Contabilidade da Universidade de São Paulo.

Hail, L. (2003). The impact of voluntarily corporate disclosure on the ex ante cost of capital for Swiss firms. European Accounting Review, v. 11, p. 741-743.

Healy, P. M.; Palepu, K. G. (2001). Information asymmetry, corporate disclosure, and the capital markets: a review of the empirical disclosure literature. Journal of Accounting and Economics, v. 31, p. 405440. 
Hu, N.; Liu, L.; Tripathy, A.; \& Yao, L. (2011). Value relevance of blog visibility. Journal of Business Research, 64(12), 1361-1368.

Jensen, M.; Meckling, W. (1976). Theory of firm: Managerial behavior, agency costs and ownership structure. Journal of Financial Economics, v. 3, p. 305-360.

Junqueira, L. A. P. A. (2008). Gestão social: organizações parceria e redes sociais. In: CANÇADO, A. C. et al. Os desafios da formação em gestão social. Palmas, TO: Coleção Enanpegs, 2008.

Lanzana, A. (2004). Relação entre o disclosure e governança corporativa das empresas brasileiras. 165f. Dissertação (Mestrado em Administração) - Faculdade de Economia, Administração e Contabilidade, Universidade de São Paulo, São Paulo.

Leuz, C.; Verrecchia, R. (2000). The economic consequences of increased disclosure. Journal of Accounting Research, v. 38, p. 91-124.

Lima, G. (2007). Utilização da Teoria da Divulgação para avaliação da relação do nível de disclosure com o custo da dívida das empresas brasileira. 118 p. Tese (Doutorado em Controladoria e Contabilidade) - Faculdade de Economia, Administração e Contabilidade, Universidade de São Paulo, São Paulo.

Lima, G. A. S. D et al. (2014). Características Explicativas do Nível de Disclosure Voluntário de Municípios do Estado de Minas Gerais. RACE, Unoesc, v.13, n.2, p. 571-608, maio/ago.

Machado, E.A.; Morch, R.B.; Vianna, D.S.C.; Santos, R.; Siqueira, J.R.M. (2009). Destinação de riqueza aos empregados no Brasil: comparação entre empresas estatais e privadas do setor elétrico (20042007). Revista Contabilidade E Finanças, USP, São Paulo, v. 20, n. 50, p. 110-122, maio/agosto.

Mendes-da-Silva, Wesley; Onusic, Luciana Massaro; Bergmann, Daniel Reed. (2014). The influence of e-disclosure on the ex-ante cost of capital os listed companies in Brazil. Journal of Emerging Market Finance, 13.3, 335-365.

Moraes, E. A.; Gonçalves, R.S.; Niyama, J.K. (2015). Ambiente regulatório e evidenciação social: uma análise das divulgações de empresas brasileiras listadas na BM\&FBovespa. Advances in Scientific and Applied Accounting. São Paulo v.8, n.2 p. 218 - 243 Mai /Ago.

Murcia, F. D.; Santos, A. (2009). Fatores determinantes do nível de disclosure voluntário das companhias abertas no Brasil. Revista de Educação e Pesquisa em Contabilidade, v.03, n.02, p. 72-95, maio/ago.

Nakaiama, W.K.; Salotti, B. M. (2014). Fatores determinantes do nível de divulgação de informações sobre combinações de negócios com a entrada em vigor do pronunciamento técnico CPC 15. Revista Contabilidade E Finanças, USP, São Paulo. v. 25, n. 66, p. 267-280, set./out./nov./dez.

Ribeiro, A.M. Bellen, H.M.V.; Carvalho, L.N.G. (2011). Regulamentar faz diferença? O caso da evidenciação ambiental. Revista Contabilidade E Finanças, USP, São Paulo. v. 22, n. 56, p. 137-154, maio/jun./jul./ago. 
Salotti, B. M., \& Yamamoto, M. M. (2005). Ensaio sobre a teoria da divulgação. BBR Brazilian Business Review, 2(1), 53-70.

Salotti, B. M. (2005). Divulgação voluntária da demonstração dos fluxos de caixa no mercado de capitais brasileiro. Tese (Doutorado em Ciências Contábeis) - Programa de Pós-Graduação em Ciências Contábeis, Departamento de Contabilidade e Atuária, Faculdade de Economia, Administração e Contabilidade da Universidade de São Paulo.

Silva, T. L.; Alberton, L. Vicente, E. F. R. (2013). Práticas de disclosure voluntário das empresas do setor elétrico: uma análise a partir do modelo de Murcia. Revista Catarinense da Ciência Contábil. v. 12, n. 35 , p. 48-62, abr-jul.

Tinoco, J. E. P.; Kraemer, M. E. P. (2004). Contabilidade e gestão ambiental. São Paulo: Atlas.

Verrecchia, R. (2001). Essays on disclosure. Journal of Accounting and Economics, v. 22, p. 97-180.

Welker, M. (1995). Disclosure policy, information asymmetry, and liquidity in equity markets. Contemporary Accounting Research, v. 11, p. 801-827.

Yamamoto, M. M. (2005). Teoria da divulgação aplicada ao mercado de capitais brasileiro sob a perspectiva da governança corporativa. Tese de Livre Docência apresentada ao Departamento de Contabilidade e Atuária da Faculdade de Economia, Administração e Contabilidade da Universidade de São Paulo. São Paulo.

Yamamoto, M. M.; Salotti, Bruno Meirelles. (2006). Informação contábil: estudos sobre a sua divulgação no mercado de capitais. São Paulo: Atlas. 